\title{
TWO PORTS LAPAROSCOPIC CLIPPING RELEASE IN SITU CASTRATION TECHNIQUE IN LATERAL RECUMBENT DONKEYS
}

\author{
EL-KHAMARY A. N. ${ }^{1}$; EL-SHERIF M.W. ${ }^{2}$; MOHAMED ABUMANDOUR M.A. ${ }^{3}$; \\ SAYED-AHMED A.S. ${ }^{4}$ and ABD EL-WAHED R.E. ${ }^{5}$ \\ ${ }^{1}$ Department of Surgery, Faculty of Veterinary Medicine Damanhur University, Egypt \\ ${ }^{2}$ Department of Surgery, Faculty of Veterinary Medicine, New Valley, Assiut University, Egypt. \\ ${ }^{3}$ Anatomy and Embryology Department, Faculty of Veterinary Medicine, Alexandria University, Egypt. \\ ${ }^{4}$ Anatomy and Embryology Department, Faculty of Veterinary Medicine, Damanhour University, Egypt. \\ ${ }^{5}$ Department of Surgery, Faculty of Veterinary Medicine, Alexandria University, Egypt.
}

Received: 8 March 2016; Accepted: 27 April 2016

\begin{abstract}
The objective of this study was to provide a detailed laparoscopic anatomy of the abdominal regions and to describe Laparoscopic Clipping Release (LCR) in situ castration technique in lateral recumbent male donkey. Nine adult clinically healthy donkeys were used for the study. Using only two laparoscopic ports and titanium clips to induce in situ castration in lateral recumbent generally anesthetized patients was the golden change out of previous laparoscopic trials. The main port placed 5-10 $\mathrm{cm}$ caudal to the umbilicus and secondary port placed in groin region $10 \mathrm{~cm}$ dorsal and $10 \mathrm{~cm}$ caudal to the main port. Two clips over the course of the vas deference and four clips over the course of the testicular blood vessels (one pair dorsally and one pair ventrally) are fixed using clip applier. This technique provided an optimal access, easy manipulation and handling of testicular structures, short operative time, no intra or post-operative complications and excellent cosmetic appearance. We concluded that LCR technique in right lateral recumbent position is proved to be feasible, safe, less time consuming, and could be brought into consideration as an alternative to in situ equine castration methods.
\end{abstract}

Key words: Donkeys, Castration, Laparoscopy, Clipping and Lateral Recumbent.

\section{INTRODUCTION}

Compared to conventional castration methods, the laparoscopic castration technique shows minimal intra and post-operative complications (Fischer and Vachon 1992; Davis 1997; Walmsley 2003 and Pepe et al., 2005). The technique of leaving the testis in situ to undergo avascular necrosis decreases the potential for excess oedema, haemorrhage, infection, lameness and evisceration, when compared with other methods (Moll et al., 1995; Wilson et al., 1996 and Bergeron et al., 1998). Swelling and signs of pain observed after laparoscopic surgery are less severe than those seen after routine castration and are an expected response to the necrotic testicular tissue (Wilson et al., 1996).

Corresponding author: Dr. EL-SHERIF M.W.

E-mail address: drmwt@hotmail.com

Present address: Department of Surgery, Faculty of Veterinary Medicine, New Valley, Assiut University, Egypt.
Laparoscopic in situ castration can be performed through ligation transection, electrosurgical coagulation and transection and endoscopic stapling of the spermatic cord (Turner and Brown 1993; Fischer 1998; Hanrath and Rodgerson 2002 and pepe et al., 2005). Ligation technique was reported with a disadvantage of being time consuming and ability of knot slippage, while electro cauterization shows high efficiency in small diameter blood vessels and with a probable failure in large ones and accidental organ perforation (Freeman, 1999).

There are numerous techniques for laparoscopic castration of cryptorchide testis which have been described, but there are principal differences related to position of the horse (standing or dorsal recumbency) (Galuppo et al., 1996; Wilson et al., 1996; Hendrickson, 2006 and Rubio-Martinez, 2012).

Laparoscopic in situ castration in anesthetized dorsal recumbent donkeys is more advantageous than in standing position because no additional portals are required for manipulating the spermatic cord and shorter surgical time. For the standing approach the need to use both flanks was a must, it also requires 
additional preparation time and results in poor visualization of the spermatic cord in some cases because of impairment of some abdominal structures (Pepe et al., 2005 and Greet, 2008).

Despite the advantages of dorsal recumbent laparoscopic surgery; it may result in serious complications due to patient's position and anesthesia protocol that have adverse effects on arterial oxygenation and respiratory function Hofmeister et al. (2008) and Dijk et al. (2015).

The aim of this study was to provide a detailed laparoscopic anatomy of the abdominal organs and to describe Laparoscopic Clipping Release (LCR) in situ castration technique in lateral recumbent male donkey as a modified technique of laparoscopic in situ castration.

\section{MATERIALS AND METHODS}

\section{Animals:}

The present study was carried out on 9 adult apparently healthy local breed donkeys weighting 200-250 kg and aged from 7-9 years old with normal descended scrotal testis. Two donkeys were used for laparoscopic anatomical evaluation of both sides of the abdomen and then 7 donkeys were used for laparoscopic in situ castration.

\section{Laparoscopic Equipment and Instrumentation:}

Standard laparoscopic instruments, cannulas, telescope, insufflator, Veress needle, Maryland grasper, scissors and Endo clip applier (Endoservice, GmbH, Germany) and medium/large titanium clips (Ethicon, USA). Operating instruments were available in $45-\mathrm{cm}$ length and $10-\mathrm{mm}$ diameter.

\section{Animal Preparation:}

All donkeys had a standard preoperative clinical examination including careful palpation of the external reproductive tract to confirm the presence of
2 normally descended scrotal testes. Food was withheld for 24-36 hours while water was allowed ad lib before surgery. A single dose of 3000 IU of tetanus antitoxin, 10,000 IU/kg Procaine Penicillin G plus $10 \mathrm{mg}$ of streptomycin/ kg (Combi-Kel, Kela Laboratoria, Belgium), and $1.1 \mathrm{mg} / \mathrm{kg}$ non-steriodal anti-inflammatory flunixin meglumine (Finadyne, Intervet Shering-Plough Animal Health) were administered before the laparoscopic procedures.

All animals were anesthetized by intravenous administration of xylazine $\mathrm{Hcl}$ (Xylaject, ADWIA, Egypt.) in a dose of $1.1 \mathrm{mg} / \mathrm{Kg}$ of body weight followed by intravenous administration of Ketamine Hcl (Ketamine, Sigmatech Pharm, Egypt) in a dose of $2.2 \mathrm{mg} / \mathrm{Kg}$ of body weight with 5 minutes apart.

\section{Laparoscopic anatomy of lateral recumbent position:}

Donkeys were restrained and positioned firstly in right lateral recumbency with the hindquarter tilted upward 15 degrees (Trendelenburg position). The abdomen was prepared and draped for aseptic procedure then the left hind limb was draped and hanged to the ceiling. The main portal cannula placed $5-10 \mathrm{~cm}$ caudal to the umbilicus by an open technique according to Palmer (1993). Abdominal insufflation and introducing the laparoscope via the main portal were achieved to explore the anatomical structures of the abdominal organs systematically from caudal to cranial in lateral recumbent position. The procedure was repeated on the opposite side.

\section{Laparoscopic Clipping Release (LCR) in situ castration:}

In right lateral recumbency, two instrumental portals were made. The first portal was placed as the procedure aforementioned in laparoscopic anatomy. A second $10 \mathrm{~mm}$ portal cannula was placed in the groin region $10 \mathrm{~cm}$ dorsal and caudal to the level of the main portal (Fig.1). The secondary portal was used to introduce a $10 \mathrm{~mm}$ clip applier.

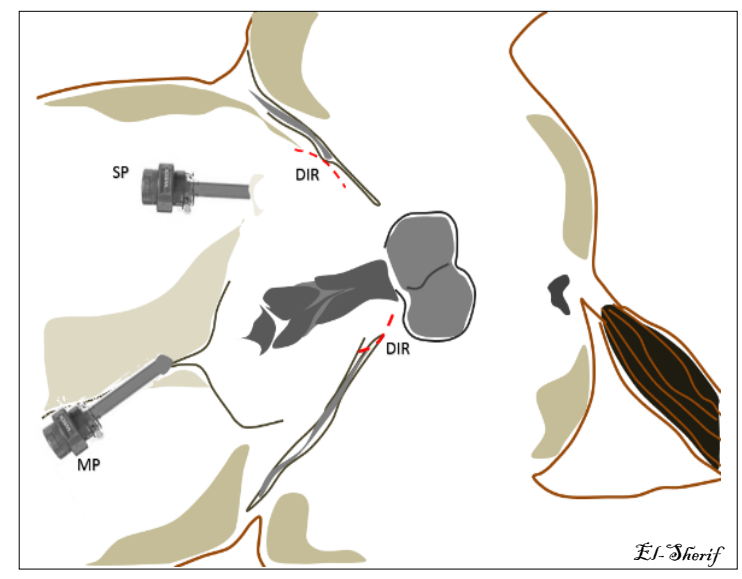

Fig.1: Showing the animal laid in right lateral recumbent position with the upper limb hanged. The main port (MP) introduced via umbilicus and a secondary port (SP) in the groin region. Red dotted lines referred to deep inguinal rings (DIR). 
Two clips were fixed over the course of the vas deference with 1-2 cm in between. Another four clips were placed over the course of mesorchium without dissection from the abdominal wall; one pair dorsally and one pair ventrally with $2 \mathrm{~cm}$ in between. The clip applier was then substituted with a scissors to transect the vas deference and mesorchium between the clips. The operation site and stumps were examined carefully for bleeding (Fig. 2).

Laparoscopic procedure was evaluated considering: operative time, Intra operative complication(s) and degree of easiness. Operative time was measured in minutes from the time of main port insertion to placement of last skin suture. Intra operative complication(s) including organ puncture and bleeding were recorded. Bleeding was determined according to the score described by (Culp et al., and Dupré et al., 2009) such as; None: no bleeding, Minor: presence of few drops of blood that stopped immediately and required no hemostatic interventions, Moderate: the present blood did not obscure the surgical field but required hemostatic intervention and severe: the bleeding impaired the observation of the surgical field and required either hemostasis or conversion to laparotomy.
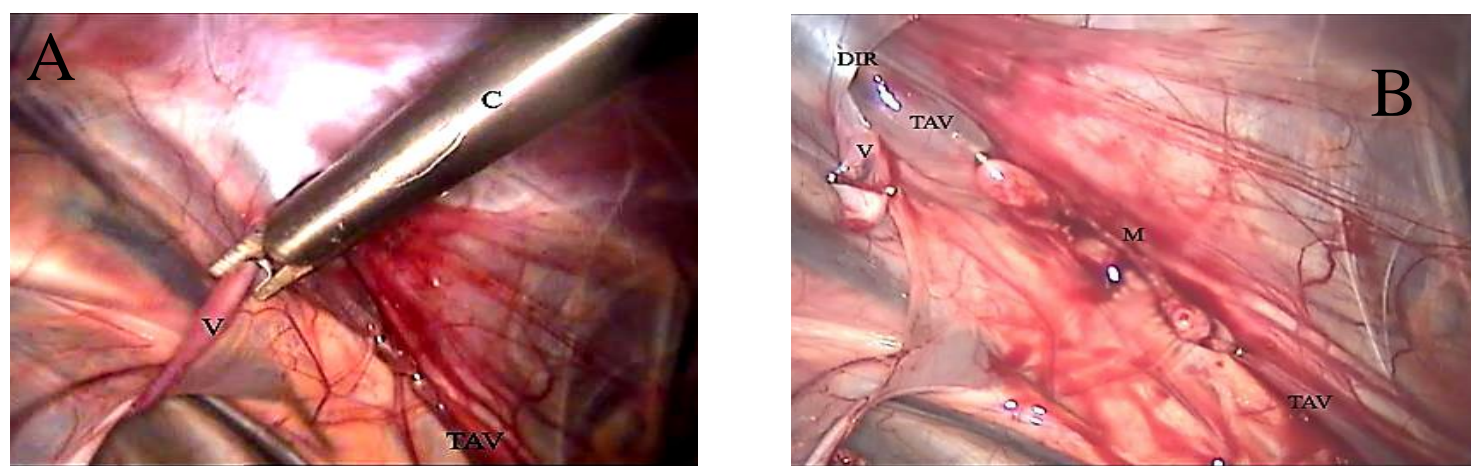

Fig. 2: (A) Showing the application of titanium clips over the course of testicular blood vessles and vas deference by using clip applier. (B) Showing transection of vas deference and testicular blood vessles. (V) vas deference, (C) clip applier, (TAV) testicular artery and vein, (DIR) deep inguinal ring, (M) mesorechium.

Degree of easiness of the procedure was measured by scores from 0-3 (where; 0: means too easy and no effort is exerted upon the surgeon, 1: means easy, 2: means difficult, and 3: means too difficult to be completed and required traditional surgery. Selection of these scores to describe the degree of easiness based on observation and determination of the following; number of portals and trocars, viewing of the laparoscopic field, organ accessibility, handling of tissues as well as number of hand instrument confliction.

\section{Postoperative management:}

After surgery, all operated donkeys were kept in a small paddock for 5 days in conjunction with daily controlled walking for 20 minutes. Special attention was paid to the scrotal area during the first 15 days post operation followed by re-laparoscopic examination to detect inflammation, hematoma formation or adhesions. All collected data was analyzed statistically according to SAS (2006).

\section{RESULTS}

\section{Laparoscopic Anatomy:}

Laparoscopic exploration of the lateral recumbent animals revealed that the main structures in the left side of the abdomen included; the hepatic duct, left lateral and quadrate lobes of the liver, stomach, spleen, left kidney with the associated nephrosplenic ligament, segments of jejunum, descending colon, and ascending colon, left side of the male reproductive tracts, urinary bladder, inguinal ring, and mesorchium.

While structures observed in the right side of the abdomen included; portion of the common hepatic duct, left lateral, quadrate, and right lobes of the liver, caudate process of the liver, stomach, duodenum, right dorsal colon, epiploic foramen, omental bursa, right kidney, base of the cecum, segments of jejunum, descending colon, and ascending colon, urinary bladder, right half of the male reproductive tracts, and rectum (Fig. $3 \mathrm{~A}$ and $\mathrm{B}$ ). 

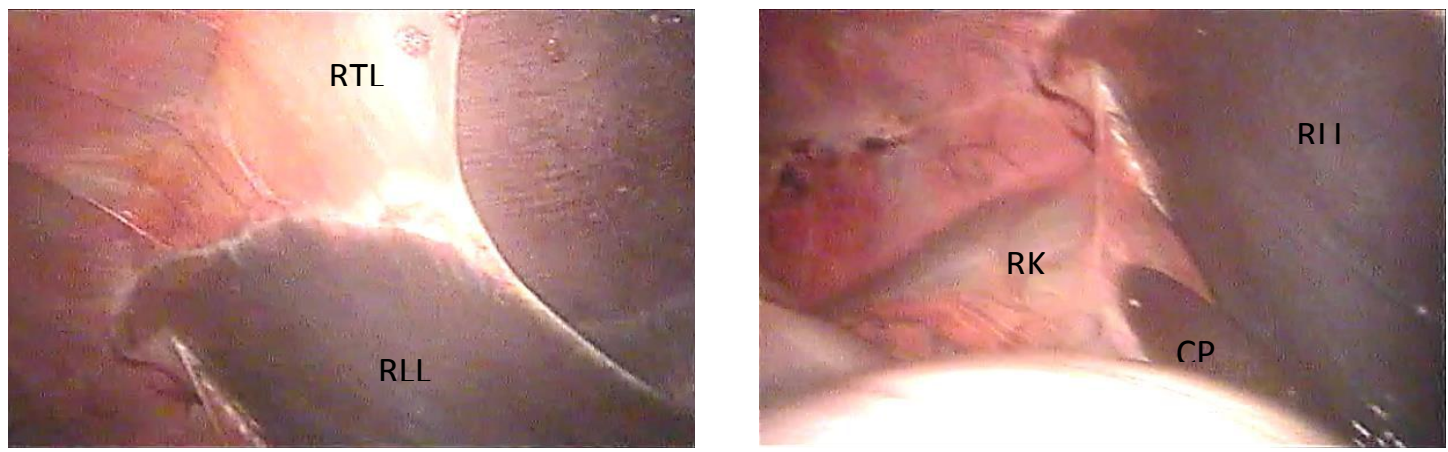

Fig. 3: A. Laparoscopic anatomy of right cranial portion of the abdomen showing (RLL) right lateral lope of liver, (RTL) right triangular ligament, (RK) right kidney, (CP) caudate process of liver.
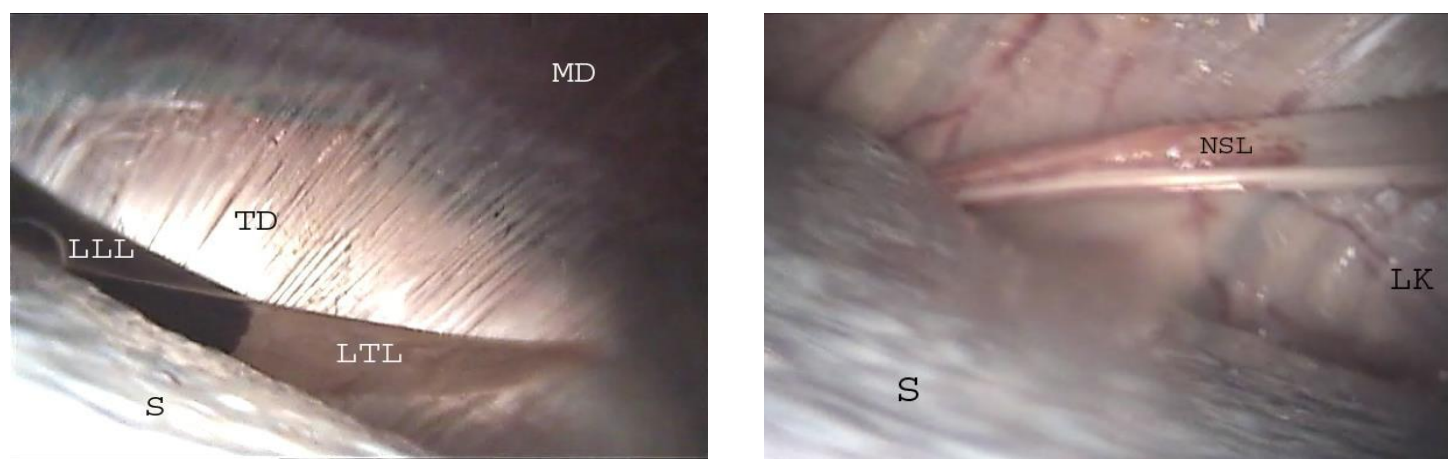

Fig. 3: B. Laparoscopic anatomy of left cranial portion of the abdomen showing (LLL) left lateral lope of liver, (LTL) left triangular ligament, (TD) tendinious portion of diaphragm, (MD) muscular portion of diaphragm, (S) spleen, (LK) left kidney and (NSL) nephrosplenic ligament.

The right lateral Trendelenburg position was found to be more convenient than the left position (fig. $3 \mathrm{C}$ ).

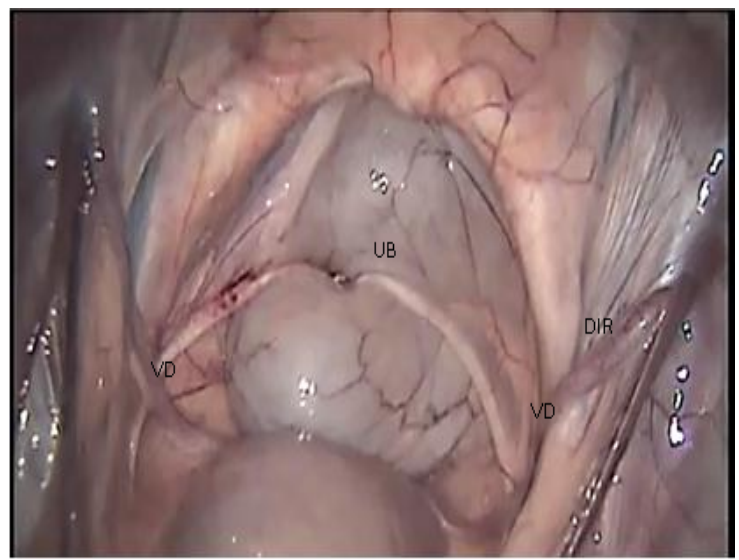

Fig. 3: C. Laparoscopic anatomy of caudal portion of the abdomen (pelvic cavity) as seen in left lateral recumbent patient showing (UB) urinary bladder, (VD) vas deference, (TAV) testicular artery and vein and (DIR) deep inguinal ring.

Laparoscopic Clipping Release (LCR) in situ castration: 
Withholding food 24 to 36 hours, aids to reduce bulk in the peritoneal cavity and improve the working space, hence with the aid of a light pneumoperitoneum (12 $\mathrm{mm} / \mathrm{hg})$ provided more roomy space for intra-abdominal laparoscopic intervention.

The right lateral recumbent Trendelenburg position of 15 degrees provided an optimal view to the two inguinal rings and their contents of vas deferens and mesorchium and offered a comfortable instrumental handling for the surgeon. Further advantages of RLT position were better animal-surgeon-set layout and only one surgeon can perform without assistance.

The procedure was feasible and the degree of effort exerted up on the surgeon during procedure scored between 0 and 1 . Mean operative time $(\mathrm{M} \pm \mathrm{SD})$ recorded $12 \pm 3$ minutes (ranged from 10 to 15 minutes).

The medium/ large endoscopic titanium clips were suitable to occlude the mesorachium up to $8.1 \mathrm{~mm}$ in diameter, easily applied and fast. There were neither bleeding nor organ perforation as intra-operative complications. On re-laparoscopic examination, neither visible postoperative complications nor clip slippage were recorded.

All testes were slightly increased in size, get warm and painless on manual palpation during the 1st week postoperative. Thereafter, the scrotal size began to decrease and around 15 days after castration, the swelling was no longer obvious.

The modified LCR was proved to be a feasible, easy, time-saving with minimal complications technique.

\section{DISCUSSION}

After the thorough laparoscopic anatomical exploration of the abdomen in both right and left lateral recumbent positions, the right lateral Trendelenburg position was found to be more convenient than the left position because cecum was not incorporated in the surgical field. This result was similar to that obtained by Galuppo et al. (1995) and Galuppo (2002).

In contrast to laparoscopic castration of Sardinia donkeys in standing and dorsal recumbent positions reported by Pepe et al. (2005), the current technique was more fast, easy and safe. The advantages of the technique seem to be a result of reduced number of ports and minimal manipulation of spermatic cords. Moreover, changing the patient position to right lateral Trendelenburg position offers a direct panoramic visualization of the surgical field and minimizes the tilting degree of patient's head, therefore the risk of pneum-heamodynamic consequences decrease. These findings were in agreement with Hofmeister et al. (2008) and Dijk et al. (2015).

Furthermore, we have found this position versatile, useful and adaptable to any operation theater. It is an acceptable alternative, and in our experience, a distinct improvement over the dorsal recumbent position performed by Pepe et al. (2005). The current position offered more specific advantages such as: (1) with the surgeon's eye, the camera, the operative field, and the monitor aligned in one line, optimal eye-hand coordination is achieved. (2) Since the patients' hips are not flexed and abducted, the range and freedom of movement of the surgeon is greatly increased (3) The theater layout are the same as those used for the traditional castration position (4) If a conversion to open surgery is required, it could be performed without altering the patient's position or surgical drapes (5) One surgeon can perform operation successively without any assistance of camera operator or assistant surgeon because of comfortable approximated level of hand-port layout.

Considering the time factor and easiness of the technique, the application of medium/ large titanium clips for mesorchium and vas deference appeared technically efficient, easy and time saving. The mesorchium was completely involved within the jaws of the clip and no bleeding was recorded after vessels transection. Moreover, use of the medium/large titanium clip resulted in improved surgical time compared with other techniques reported by Fischer (1998) and Hanrath and Rodgerson (2002) that using endoscopic sutures loops or/and electrosurgical dissection and hemostasis.

Laparoscopic-Clipping-Release (LCR) in situ castration technique was successively achieved in anesthetized right lateral Trendelenburg recumbent donkeys. The spermatic cord was easily recognized, occluded and transected without any complications. To our knowledge, the present study is the first documented trial describing the laparoscopic in situ castration in a modified lateral recumbent position in donkeys.

In agreement with the previous reports in horses, the potential advantages of laparoscopic castration in donkeys include: (1) a smaller incision, (2) better visualization of the important structures, (3) tensionfree transection of the mesorchium, (4) easy evaluation of the transected stump to make sure there is no hemorrhage, which generally leads to less postoperative pain and morbidity compared with open surgical castration as reported by Nicola et al. (2015).

It should be noted that in situ castration has conflicting results. Pepe et al., 2005; Saifzadeh et al., 
2008 and Abou-Ahmed et al. (2012) reported that the spermatic cord transection induced avascular necrosis of testicular tissue, without revascularization of the testes based on serum testosterone concentrations and histological evaluation 3-12 months after surgery. On the other hand, Voermans et al. (2006) and Fourmestraux et al. (2014) recorded that testis revascularization occurred in 7-12.5\% of cases originated from anastomosing vessels of the external pudendal artery through the proper ligament of the testis.

Despite the fact that geldings in this report had none of the major complications reported with traditional castration methods, a more comprehensive long-term comparative study should be undertaken to understand fully the pro and cons of this technique.

Based on the over mentioned results, LCR technique in right lateral recumbent position reported here is proved to be readily accomplished, safe, less-time consuming, and could be brought into consideration as an alternative to the in situ equine castration methods.

\section{REFERENCES}

Abou-Ahmed et al, (2012): Comparative Evaluation of three in situ castration techniques for Sterilizing Donkeys: Incision-Ligation (a Novel Technique), Section-Ligation-Release, and Pinhole. Journal of Equine Veterinary Science; 32 (11): 711-718.

Bergeron, AJ.; Hendrickson, A. and McCue, MP. (1998): Viability of an inguinal testis after laparoscopic cauterization and transection of its blood supply. J. Am. Vet. Med. Res., 213: 1303-1304.

Culp, WT.; Mayhew, PD. and Brown, DC. (2009): The effect of laparoscopic versus open ovariectomy on postsurgical activity in small dogs. Vet. Surg.; 38 (7): 811-817.

Davis, EW. (1997): Laparoscopic cryptorchidectomy in standing horses. Vet. Surg., 26 (4): 326-331.

Dijk, JV. (2015): The infiluence of of the reserved trendlinburg position on artirial oxygenation in the horse. Master desertation. Ghent University. Belgium.

Dupre, G.; Fiorbianco, V. and Skalicky, M. et al. (2009): Laparoscopic ovariectomy in dogs: comparison between single portal and twoportal access. Vet. Surg., 38 (7): 818-824.

Fischer, A. and Vachon, A. (1992): Laparoscopic cryptorchidectomy in horses. JAVMA, 201 (11): 1705-1708.

Fischer, AT. (1998): Editor. Equine diagnostic and surgical laparoscopy. Philadelphia: WB Saunders, p. 37-49, $1^{\text {st }}$ ed.

Fourmestraux, C.; Geffroy, O.; Siliart, B.; Albaric, $O$. and Tessier, $C$. (2014): Evaluation of success rate of laparoscopic castration without orchiectomy in 32 mature horses. Equine Vet. Educ. 26 (1) 34-39.

Freeman, L.J. (1999): Operating room, setup, equipment, and instrumentation. In: Freeman Lynetta J.(Ed.), Veterinary Endosurgery, Mosby, London, 3-23, $1^{\text {st }}$ ed.

Galuppo, L.D. (2002): Laparoscopic anatomy. In: Equine diagnostic and surgical laparoscopy. Editor. A T Fischer. WB Saunders, 5-15, $1^{\text {st }}$ ed.

Galuppo, L.D.; Snyder, J.R., and Pascoe, J.R. (1995): Laparoscopic anatomy of the equine abdomen. American Journal of Veterinary Research, 56, 518-531.

Galuppo, L.D.; Snyder, J.R. and Pascoe, J.R. et al. (1996): Laparoscopic Anatomy of the Abdomen in Dorsally Recumbent Horses. American Journal of Veterinary Research, 57, 923-931.

Greet, T. (2008): Laparoscopic surgery of Australian College of veterinary scientist's annual conference.

Hanrath, M. and Rodgerson, D. (2002): Laparoscopic cryptorchidectomy using electrosurgical instrumentation in standing horses. Veterinary surgery. 31, 117-124.

Hendrickson, D. (2006): Laparoscopic cryptorchidectomy and ovariectomy in horses. Vet. Clin. North Am. Equine Pract.; 22(3): 777-98.

Hofmeister, E.; Peroni, J.F. and Fischer, A.T. (2008): Effects of carbon dioxide insufflation and body position on blood gas values in horses anestheised for laparoscopy. Journal of equine veterinary scince 28 (9), 549-553.

Moll, H.; Pelzer, K.; Pleasant, R.; Modransky, P. and May, K. (1995): A survey of equine castration complications. Journal of Equine Veterinary Science 15 (12): 522-526.

Nicola, C.; Koenig, J. and Sorge, U. (2015): Comparison of laparoscopic versus conventional open cryptorchidectomies on intraoperative and postoperative complications and duration of surgery, anesthesia, and hospital stay in horses. JAVMA. 246.8.885.

Palmer, S.E. (1993): Standing laparoscopic laser technique for ovariectomy in five mares. JAVMA, 203, 297-283.

Pepe, M.; Gialletti, R.; Moriconi, F.; Puccetti, M.; Nannarone, S. and Singer, ER. (2005): Laparoscopic sterilization of Sardinia donkeys using an endoscopic stapler. Veterinary Surgery 34 (3): 260-264.

Rubio-Martinez, L.M. (2012): Standing laparoscopic castration in an equine male pseudohermaphrodite. Journal of equine veterinary education. 24 (10). 507-510.

Saifzadeh, S.; Hobbenaghi, R.; Asri-Rezaei, S.; Shokouhi, S.J.F.; Dalir-Naghadeh, $B$. 
and Rohi, S.M. (2008): Evaluation of 'SectionLigation-Release (SLR)' technique devised for castration in the stallion. Reprod Domest Anim.; 43 (6): 678-84.

Statistics analysis system (SAS) 2006.

Turner, T.T. and Brown, K.J. (1993): Spermatic cord torsion: loss of spermatogenesis despite return of blood flow. Biology of Reproduction, 49: 401-407.

Voermans, M.; Rijkenhuizen, A.B.M. and Van der Velden, M.A. (2006): The complex blood supply to the equine testis as a cause of failure in laparoscopic castration. Equine Vet. J. 38, 35-39.

Walmsley, JP. (2003): Advantages and limitations of laparoscopy in the horse. Proceedings of the 12th ECVS meeting Glasgow., Scotland.

Wilson, D.; Hendrickson, D.; Cooley, A. and Degrave-Madigan, E. (1996): Laparoscopic methods for castration of equids. JAVMA, 209 (1): 112-11.

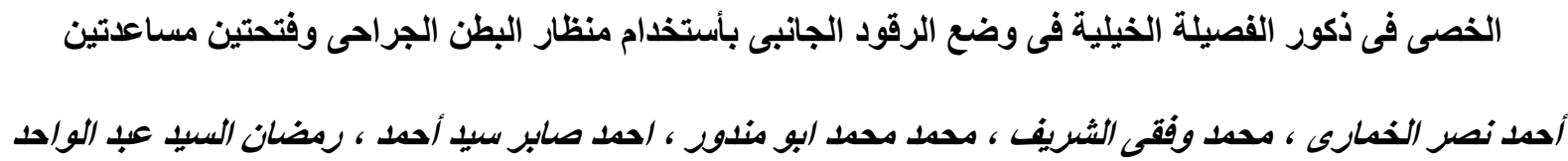

E-mail: drmwt@hotmail.com Assiut University web-site: $\underline{\text { www.aun.edu.eg }}$

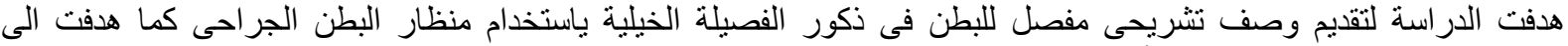

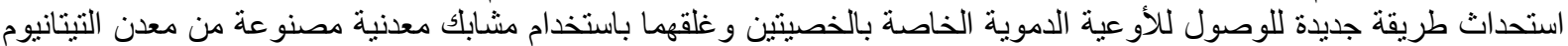

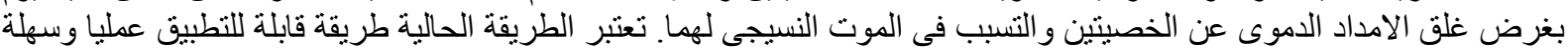

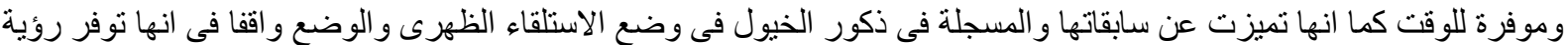

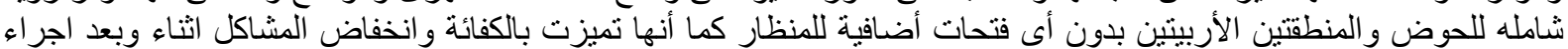

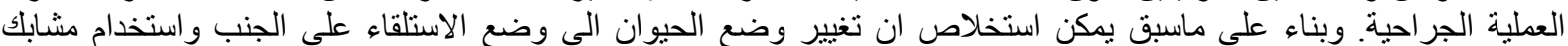
التيتانيوم هى طريق فاعلة لأحداث الموت النسيجى للخصية و إحداث العق بكفاءة وبأقل المشاكل. 